\title{
An explorative analysis of the prognostic value of lactate dehydrogenase for survival and the chemotherapeutic response in patients with advanced triple-negative breast cancer
}

\author{
Zhenya Jia ${ }^{1,2, *}$, Jian Zhang ${ }^{1, *}$, Zhonghua Wang ${ }^{1}$, Biyun Wang ${ }^{1}$, Leiping Wang ${ }^{1}$, Jun \\ $\mathrm{CaO}^{1}$, Zhonghua $\mathrm{TaO}^{1}$ and Xichun Hu${ }^{1}$ \\ ${ }^{1}$ Department of Medical Oncology, Fudan University Shanghai Cancer Center, Department of Oncology, Shanghai Medical \\ College, Fudan University, Shanghai 200032, China \\ ${ }^{2}$ Department of Oncology, The First Affiliated Hospital of Anhui Medical University, Hefei 230032, China \\ *These authors contributed equally to this work \\ Correspondence to: Jian Zhang, email: syner2000@163.com \\ Xichun Hu, email: xchu2009@hotmail.com
}

Keywords: triple-negative breast cancer; lactate dehydrogenase; metastasis; prognosis

Received: November 18, $2016 \quad$ Accepted: December 05, $2017 \quad$ Published: January 13, 2018

Copyright: Jia et al. This is an open-access article distributed under the terms of the Creative Commons Attribution License 3.0 (CC BY 3.0), which permits unrestricted use, distribution, and reproduction in any medium, provided the original author and source are credited.

\section{ABSTRACT}

Serum lactate dehydrogenase (LDH) level is predictive of prognosis in various malignancies. Nevertheless, the association between the prognosis of patients with advanced triple-negative breast cancer (TNBC) and LDH is not well understood. This explorative and retrospective study was conducted to clarify the issue. We found that abnormal baseline LDH levels ( $>250 \mathrm{IU} / \mathrm{L}$ ) were significantly associated with age ( $>40$ y vs. $\leq 40$ y, OR: $0.383, P=0.031$ ) and number of metastatic sites ( 2 vs. 1 , OR: $4.619, P=0.006 ; \geq 3$ vs. 1, OR: $4.727, P=0.002$ ). The progression-free survival (PFS) of patients with post-treatment LDH higher than baseline (Group 1) was significantly shorter than that in patients with LDH decreased to normal (Group 3 ) and those with normal baseline and post-treatment LDH (Group 4) (Group 3 vs. Group 1, HR: 0.517, $P=0.038$; Group 4 vs. Group 1, HR: $0.346, P<0.001$ ). Overall survival (OS) in patients with abnormal baseline LDH was significantly shorter than in patients with normal baseline LDH (abnormal vs. normal, HR: 2.073, $P<0.001$ ). Patients whose post-treatment LDH decreased to normal had the most objective response (complete and partial responses) rate after first-line chemotherapy (Group 3 vs. Group 1, OR: $0.074, P<\mathbf{0 . 0 0 1}$ ). In this exploratory analysis, baseline LDH levels associated with OS, while LDH changes after first-line chemotherapy associated with PFS and the chemotherapeutic response. These results show that LDH may have important prognostic value for the survival and chemotherapeutic response in patients with advanced TNBC.

\section{INTRODUCTION}

Breast cancer is the second leading cause of cancerrelated deaths in women and is the most common cancer in females, accounting for $23 \%$ of all cancer cases [1, 2]. Triple-negative breast cancer (TNBC) is a subtype characterized by the lack of estrogen receptor (ER), progesterone receptor (PR), and human epidermal growth factor receptor 2 (HER-2) expression, as confirmed by immunohistochemistry or fluorescent in situ hybridization.
TNBC is associated with a poor prognosis due to its more aggressive behavior, higher recurrence, generation of more metastases, and fewer treatment options compared with other breast cancer subtypes [3]. Cytotoxic chemotherapy remains the mainstay of treatment for TNBC, and metastatic organ sites and disease-free interval (DFI) are thought to be prognostic factors of advanced disease [4].

Serum lactate dehydrogenase (LDH) converts pyruvate to lactate in the cytoplasm during glycolysis and is thought to be a marker of tissue injury, inflammation, 
hemolysis, and myocardial damage [5-7]. In addition, abnormally high serum levels of LDH are predictive of prognosis in various malignancies [8] and are associated with breast cancer patient survival [4, 9-10]. Nevertheless, the association between advanced TNBC and serum LDH is not well understood; thus, we conducted an explorative study to determine the potential relationship.

\section{RESULTS}

All patients received a platinum-based or taxanebased regimen as first-line treatment (Table 1). In our daily practice, the previously used drugs will not be reapplied in those patients experiencing relapse within 3 months after completing neo-adjuvant or adjuvant chemotherapies. Table 2 shows the association between baseline serum LDH levels and clinical characteristics. Age ( $>40$ y vs. $\leq 40 \mathrm{y}$, odds ratio [OR]: $0.383,95 \%$ confidence interval [CI]: 0.160-0.918, $P$ $=0.031)$ and number of metastatic sites ( 2 vs. 1, OR: 4.619, $95 \%$ CI: $1.558-13.694, P=0.006 ; \geq 3$ vs. 1, OR: $4.727,95 \%$ CI: $1.777-12.570, P=0.002)$ independently associated with abnormally high baseline serum LDH levels above normal. Univariate analyses revealed that DFI, number of metastatic sites, chemotherapeutic response, and LDH changes were potential prognostic factors for PFS (Table 3), and DFI, number of metastatic sites, liver, skeletal and lymph node metastases, chemotherapeutic response, and baseline serum $\mathrm{LDH}$ and LDH changes were potential prognosis factors for OS (Table 4). PFS and OS of different groups are shown in Figures 1 and 2. Patients with abnormally high baseline serum LDH levels above normal had significantly shorter OS (unadjusted HR: 2.192, 95\% CI: 1.504-3.194, $P<$ 0.001 ) but no difference in PFS (unadjusted HR: $1.237,95 \%$ CI: $0.837-1.828, P=0.284)$ compared to those with normal baseline serum LDH levels (Figure 1).

Using the Cox regression model, we found that the independent prognostic factors of PFS for advanced TNBC patients were DFI ( $\leq 12$ mon vs. $>12$ mon, HR: $1.976,95 \%$ CI: $1.300-3.003, P=0.001$ ), chemotherapeutic response (no vs. yes, HR: $2.684,95 \% \mathrm{CI}: 1.787-4.032, P<0.001$ ), and LDH changes (Group 3 vs. Group 1, HR: 0.517, 95\% CI: $0.278-0.963, P=0.038$; Group 4 vs. Group1, HR: 0.346, 95\% CI: $0.204-0.587, P<0.001)$. The difference in OS among the four groups defined by LDH changes in Figure 2 disappeared when adjusted with other variables identified by univariate analysis with $P<0.1$ (DFI, number of metastatic sites, liver metastases, skeletal metastases, lymph nodes metastases, chemotherapy response, and baseline LDH level). Actually, only DFI ( $\leq 12$ mon vs. $>12$ mon, $\mathrm{HR}=1.888$, 95\% CI: $1.252-2.848, P=0.002)$, number of metastatic sites ( 2 vs. $1,95 \%$ CI: $1.805-3.118, P=0.024 ; \geq 3$ vs. 1 , HR: 2.449, 95\% CI: $1.548-3.874, P<0.001)$, chemotherapeutic response (no vs. yes, HR: 1.754, 95\% CI: 1.203-2.559, $P=$ 0.004) and baseline LDH (high vs. normal, HR: 2.073, 95\% CI: $1.397-3.074, P<0.001)$ were independent prognostic factors of OS for advanced TNBC patients.
Associations between clinical characteristics and chemotherapeutic responses are summarized in Table 5. No response to chemotherapy (SD or PD) was significantly associated with the presence of liver metastases (present vs. absent, OR: 4.267, 95\% CI: $1.703-10.692, P=0.002$ ) and LDH changes (Group 3 vs. Group 1, OR: 0.074, 95\% CI: $0.018-0.311, P<0.001)$ according to logistic regression. Patients with post-treatment serum LDH that decreased to normal had the greatest ORR. With regard to ORR, Group 1 patients did not show inferiority compared to groups 2 and 4. Liver metastases and post-treatment $\mathrm{LDH}$ that decreased to normal were independently associated with ORR according to logistic regression.

\section{DISCUSSION}

Advanced TNBC is highly aggressive, with a median PFS of 3-7.7 months and a median OS of about 1 year [11-15]. Similarly, the PFS and OS in this study population were 7.9 months (95\% CI: 6.3-9.5 months) and 15.1 months (95\% CI: 13.2-17.0 months), respectively.

$\mathrm{LDH}$ is required for aerobic glycolysis and can reversibly catalyze conversion of pyruvate to lactate. Recently, serum LDH has been reported to be important in numerous malignances and is documented to be 1 of 5 risk factors in the International Prognostic Index for the diffuse large B-cell lymphoma [16]. Baseline serum LDH has also been included in TNM staging system of melanoma [17]. Furthermore, high serum LDH levels are associated with adverse outcomes in lung cancer [18], esophageal squamous cell carcinoma [19], gastric [20] and pancreatic cancer [21] and renal cell carcinoma [22]. A recent systematic review and meta-analysis identified 76 studies of various solid tumors in which higher LDH was associated with shorter OS $(\mathrm{HR}=1.7, P<0.00001)$ and shorter PFS $(\mathrm{HR}=1.75, P<0.00001)$ [23]. In addition, $\mathrm{LDH}$ is reported to be a promising predictor of effectiveness of targeted agents such as bevacizumab, vatalanib, and sorafenib [24-26].

Although multiple studies have demonstrated the prognostic value of $\mathrm{LDH}$ in various malignances, the underlying pathophysiological mechanism remains unclear. LDH is possibly translationally controlled by HIF-1 and myc, and thus is regulated by the key oncogenic processes such as the phosphatidylinositol 3-kinase/AKt/TORC1/ HIF pathway or by myc overexpression [27-29]. There is a positive feedback loop between HIF and LDH, and each can stimulate the activation of the other [30]. Moreover, HIF overexpression can activate vascular endothelial growth factor-A [31], thereby linking glycolysis and LDH to angiogenesis and cancer progression [32].

Here, we exploratively studied the association between serum LDH and prognosis of advanced TNBC patients, and found that abnormal serum LDH levels were significantly associated with metastatic sites and younger age of cancer onset. Greater metastatic sites reflect heavier 
Table 1: Baseline clinical characteristics

\begin{tabular}{|c|c|c|}
\hline Characteristics & & No. of patients (\%) \\
\hline \multirow[t]{2}{*}{ Age } & $\leq 40$ years & $31(23.7)$ \\
\hline & $>40$ years & $100(76.3)$ \\
\hline \multirow[t]{2}{*}{ Menopausal status } & Pre-menopause & $75(57.3)$ \\
\hline & Post-menopause & $56(42.7)$ \\
\hline \multirow[t]{3}{*}{ Number of metastatic sites } & 1 & $40(30.5)$ \\
\hline & 2 & $32(24.4)$ \\
\hline & $\geq 3$ & $59(45.1)$ \\
\hline \multirow[t]{2}{*}{ Liver metastases } & Absent & $94(71.8)$ \\
\hline & Present & $37(28.2)$ \\
\hline \multirow[t]{2}{*}{ Lung metastases } & Absent & $69(51.8)$ \\
\hline & Present & $63(48.1)$ \\
\hline \multirow[t]{2}{*}{ Skeletal metastases } & Absent & $83(63.4)$ \\
\hline & Present & $48(36.6)$ \\
\hline \multirow[t]{2}{*}{ Lymph node metastases } & Absent & $39(29.8)$ \\
\hline & Present & $92(70.2)$ \\
\hline \multirow[t]{3}{*}{ Disease-free survival } & $\mathrm{DFI}>12$ months & $70(53.4)$ \\
\hline & $\mathrm{DFI} \leq 12$ months & $51(38.9)$ \\
\hline & Primary metastases & $10(7.6)$ \\
\hline \multirow[t]{2}{*}{ Chemotherapy response } & Yes & $77(58.8)$ \\
\hline & No & $54(41.2)$ \\
\hline \multirow[t]{2}{*}{ Baseline serum LDH } & Normal & $77(58.8)$ \\
\hline & Abnormal & $54(41.2)$ \\
\hline \multirow[t]{4}{*}{ LDH level Changes } & Group 1: Abnormal and higher than baseline & $25(19.1)$ \\
\hline & Group 2: Did not return to normal & $16(12.2)$ \\
\hline & Group 3: Decreased to normal & $28(21.4)$ \\
\hline & Group 4: Both normal & $62(47.3)$ \\
\hline
\end{tabular}
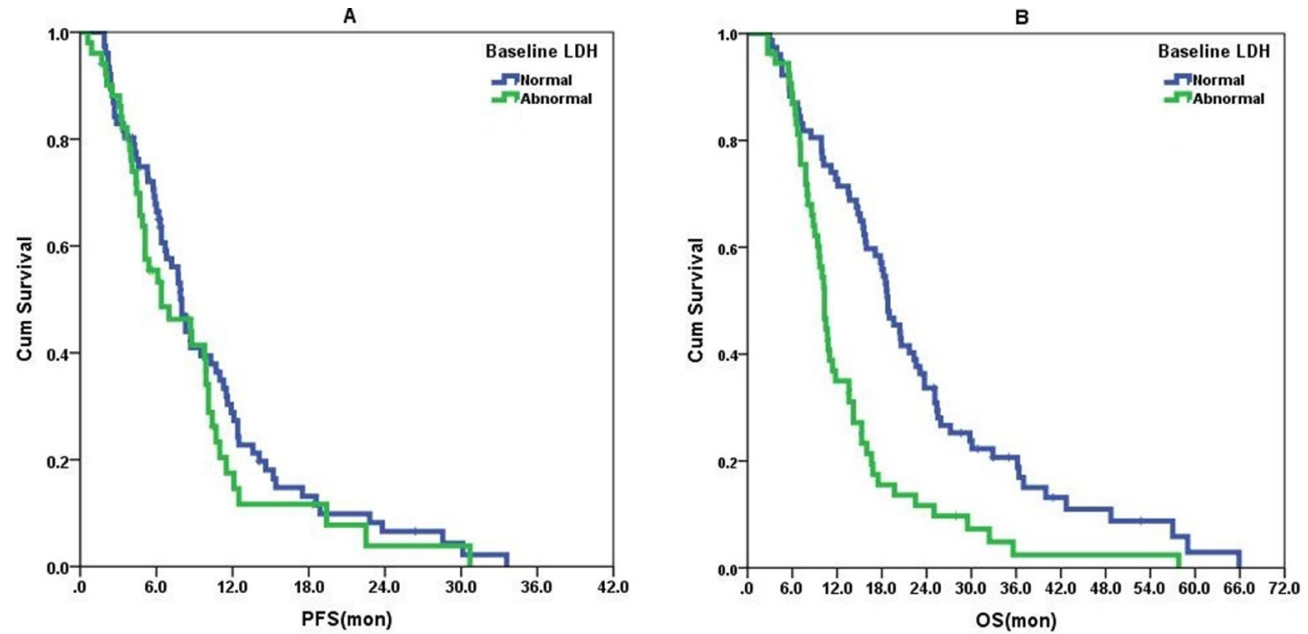

Figure 1: Baseline serum LDH level as a prognostic indicator of survival. There was no difference in PFS between advanced TNBC patients with abnormal baseline serum LDH levels $(n=54)$ and those with normal baseline serum LDH levels $(n=77)$ in $(\mathbf{A})$ (unadjusted HR: $1.237,95 \%$ CI: $0.837-1.828, P=0.284)$. Advanced TNBC patients with abnormal baseline serum LDH levels $(n=54)$ had significantly poorer OS than those with normal baseline levels $(n=77)$ in $(\mathbf{B})$ (unadjusted HR: 2.192, 95\% CI: 1.504-3.194, $P<0.001)$. 
Table 2: The difference in baseline serum LDH status (normal vs abnormal) according to various baseline characteristics

\begin{tabular}{|c|c|c|c|c|c|}
\hline \multirow[b]{2}{*}{ Variables } & \multicolumn{3}{|c|}{ Baseline serum LDH status } & \multicolumn{2}{|c|}{ Logistic regression model } \\
\hline & $\begin{array}{c}\text { Normal } \\
(\leq 250 \mathrm{IU} / \mathrm{L}) \\
n(\%)\end{array}$ & $\begin{array}{c}\text { Abnormal } \\
(>250 \mathrm{IU} / \mathrm{L}) \\
n(\%)\end{array}$ & $\boldsymbol{P}^{*}$ & OR $(95 \% C I)$ & $\boldsymbol{P}^{* *}$ \\
\hline Age & & & 0.009 & & \\
\hline$\leq 40$ years & $12(38.7 \%)$ & $19(61.3 \%)$ & & Ref. & \\
\hline$>40$ years & $65(65.0 \%)$ & $35(35.0 \%)$ & & $0.383(0.160-0.918)$ & 0.031 \\
\hline Menopausal status & & & 0.068 & & \\
\hline Pre-menopause & $39(52.0 \%)$ & $36(48.0 \%)$ & & & \\
\hline Post-menopause & $38(67.9 \%)$ & $18(32.1 \%)$ & & & \\
\hline $\begin{array}{l}\text { Number of metastatic } \\
\text { sites }\end{array}$ & & & 0.001 & & \\
\hline 1 & $33(82.5 \%)$ & $7(17.5 \%)$ & & Ref. & \\
\hline 2 & $16(50.0 \%)$ & $23(50.0 \%)$ & & $4.619(1.558-13.694)$ & 0.006 \\
\hline$\geq 3$ & $28(47.5 \%)$ & $31(52.5 \%)$ & & $4.727(1.777-12.570)$ & 0.002 \\
\hline Liver metastases & & & 0.139 & & \\
\hline Absent & $59(62.8 \%)$ & $35(37.2 \%)$ & & & \\
\hline Present & $18(48.6 \%)$ & $19(51.4 \%)$ & & & \\
\hline Lung metastases & & & 0.714 & & \\
\hline Absent & $41(60.3 \%)$ & $27(39.7 \%)$ & & & \\
\hline Present & $36(57.1 \%)$ & $27(42.9 \%)$ & & & \\
\hline Skeletal metastases & & & 0.008 & & 0.137 \\
\hline Absent & $56(67.5 \%)$ & $27(32.5 \%)$ & & & \\
\hline Present & $21(43.8 \%)$ & $27(56.3 \%)$ & & & \\
\hline Lymph node metastases & & & 0.027 & & 0.563 \\
\hline Absent & $29(74.4 \%)$ & $10(25.6 \%)$ & & & \\
\hline Present & $48(52.2 \%)$ & $44(47.8 \%)$ & & & \\
\hline Disease-free survival & & & 0.365 & & \\
\hline$>12$ months & $44(62.9 \%)$ & $26(37.1 \%)$ & & & \\
\hline$\leq 12$ months & $29(56.9 \%)$ & $22(43.1 \%)$ & & & \\
\hline Primary metastatic & $4(40.0 \%)$ & $6(60.0 \%)$ & & & \\
\hline
\end{tabular}

"chi-squared test; ${ }^{* *}$ Logistic regression model with multiple variables (age, menopausal status, number of metastatic sites, liver metastases, lung metastases, skeletal metastases, lymph node metastases, and disease-free survival)

tumor burden and younger patients tend to have poorer prognosis as compared to older patients [33,34], and our data indicated that LDH might negatively influence the progression of advanced TNBC. However, menopausal status, liver, lung, skeleton, lymph node metastases and DFI were shown to have no effect on baseline serum LDH. Few studies describe the prognostic value of serum LDH in breast cancer. Yamamoto's group ${ }^{[4]}$ reported that abnormal serum LDH was associated with poorer survival among metastatic breast cancer subjects and Brown's group ${ }^{[10]}$ confirmed that LDH was strongly correlated with survival in breast cancer patients with bone metastases. Moreover, Liu and colleague [9] reported that greater LDH predicted worse 5-year OS in non-metastatic stage II and III breast cancers. We also found significant associations between serum LDH level and prognosis of advanced TNBC patients. However, an independent prognostic value was only found with LDH changes between baseline and post-treatment for PFS and baseline LDH for OS. Patients with post-treatment serum LDH level that decreased to normal and patients who had both normal baseline and post-treatment serum LDH had significantly longer PFS than patients whose post-treatment serum LDH were abnormal and higher than baseline. In addition, patients with normal baseline serum LDH had significantly longer OS than patients with abnormal baseline serum LDH. As 
Table 3: Univariate and multivariate analysis of prognostic factors in PFS of advanced TNBC patients

\begin{tabular}{|c|c|c|c|c|}
\hline \multirow{2}{*}{ Variables } & \multicolumn{2}{|c|}{ Univariate analysis } & \multicolumn{2}{|c|}{ Multivariate analysis } \\
\hline & Median PFS(months) & $P^{*}$ & $\operatorname{HR}(95 \% C I)$ & $\boldsymbol{P}^{* *}$ \\
\hline Disease-free survival & & 0.023 & & \\
\hline$>12$ months & 11.3 & & Ref. & \\
\hline$\leq 12$ months & 7.5 & & $1.976(1.300-3.003)$ & 0.001 \\
\hline Primary metastatic & 7.50 & & $1.867(0.831-4.194)$ & 0.130 \\
\hline Number of metastatic sites & & 0.012 & & \\
\hline 1 & 12.2 & & & \\
\hline 2 & 8.7 & & & \\
\hline$\geq 3$ & 7.8 & & & \\
\hline Chemotherapy response & & $<0.001$ & & \\
\hline Yes & 11.6 & & Ref. & \\
\hline No & 6.7 & & $2.684(1.787-4.032)$ & $<0.001$ \\
\hline LDH level Changes & & 0.004 & & \\
\hline Group 1 & 6.0 & & Ref. & \\
\hline Group 2 & 7.1 & & $0.815(0.412-1.612)$ & 0.557 \\
\hline Group 3 & 9.4 & & $0.517(0.278-0.963)$ & 0.038 \\
\hline Group 4 & 11.4 & & $0.346(0.204-0.587)$ & $<0.001$ \\
\hline
\end{tabular}

${ }^{*}$ Log-rank test; ${ }^{* *}$ Cox regression model with multiple variables(disease-free survival, number of metastatic sites, chemotherapy response and LDH level Changes)

mentioned earlier, abnormal serum LDH might have a negative effect on the progression of advanced TNBC, and this may partially explain why patients with normal posttreatment serum LDH level had better survival outcomes.

Decreases in LDH may reflect cessation of tumor growth, while increases are associated with tumor progression [35]. In this study, most of the 28 patients with post-treatment LDH that decreased to normal after chemotherapy, had a good response to chemotherapy (PR or CR), and ORR was significantly higher than that in patients with abnormal post-treatment serum LDH

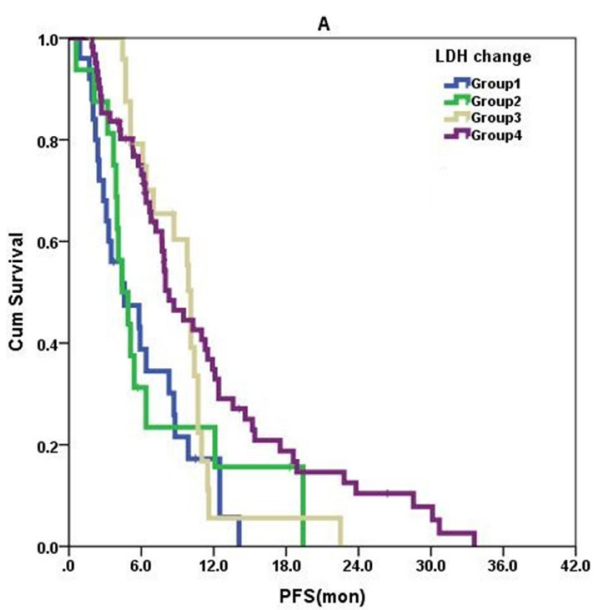

higher than baseline. This suggested that LDH changes after chemotherapy reflect tumor regression. However, no significant advantages were found for patients with post-treatment LDH that did not decline to normal and patients with both normal baseline and post-treatment LDH. Likely tumor regression occurred with the rapid and dramatic fall in LDH and this might explain why patients whose post-treatment LDH decreased to normal had longer PFS.

Therefore, serum LDH may be a useful biomarker to predict survival and chemotherapeutic response in

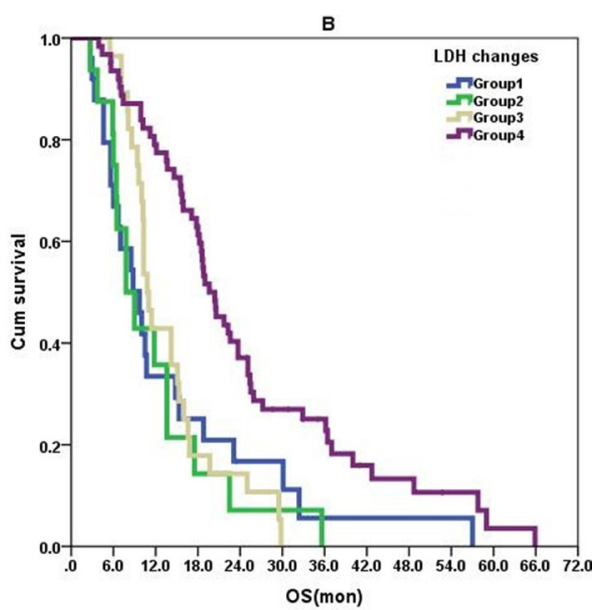

Figure 2: Serum LDH level changes as the prognostic variable in survival curves. There was a significant difference in PFS among the four groups defined by the changes of serum LDH in $(\mathbf{A})(P=0.004)$ even if adjusted with other variables. However, the difference in OS among the four groups in $(\mathbf{B})(P<0.001)$ disappears when adjusted. Group 1: Abnormal and higher than baseline; Group 2: Did not return to normal; Group 3: Decreased to normal; Group 4: Both normal. 
Table 4: Univariate and multivariate analysis of prognostic factors in OS of advanced TNBC patients

\begin{tabular}{|c|c|c|c|c|}
\hline \multirow[b]{2}{*}{ Variables } & \multicolumn{2}{|c|}{ Univariate analysis } & \multicolumn{2}{|c|}{ Multivariate analysis } \\
\hline & $\begin{array}{l}\text { Median } \\
\text { OS(months) }\end{array}$ & $\boldsymbol{P}^{*}$ & HR(95\%CI) & $\boldsymbol{P}^{* *}$ \\
\hline Disease-free survival & & 0.002 & & \\
\hline$>12$ months & 23.2 & & Ref. & \\
\hline$\leq 12$ months & 14.7 & & $1.888(1.252-2.848)$ & 0.002 \\
\hline Primary metastatic & 13.6 & & $1.571(0.788-3.132)$ & 0.119 \\
\hline Number of metastatic sites & & $<0.001$ & & \\
\hline 1 & 27.7 & & Ref. & \\
\hline 2 & 18.9 & & $1.839(1.805-3.118)$ & 0.024 \\
\hline$\geq 3$ & 13.1 & & $2.449(1.548-3.874<$ & $<0.001$ \\
\hline Liver metastases & & 0.005 & & \\
\hline Absent & 21.0 & & & \\
\hline Present & 13.6 & & & \\
\hline Skeletal metastases & & 0.004 & & \\
\hline Absent & 21.5 & & & \\
\hline Present & 14.3 & & & \\
\hline Lymph nodes metastases & & 0.001 & & \\
\hline Absent & 26.3 & & & \\
\hline Present & 15.7 & & & \\
\hline Chemotherapy response & & 0.019 & & \\
\hline Yes & 21.3 & & Ref. & \\
\hline No & 15.4 & & $1.754(1.203-2.559)$ & 0.004 \\
\hline Baseline LDH level & & $<0.001$ & & \\
\hline Normal & 22.8 & & Ref. & \\
\hline Abnormal & 13.4 & & $2.073(1.397-3.074)$ & $<0.001$ \\
\hline LDH level Changes & & $<0.001$ & & \\
\hline Group 1 & 13.9 & & & \\
\hline Group 2 & 11.8 & & & \\
\hline Group 3 & 14.2 & & & \\
\hline Group 4 & 24.9 & & & \\
\hline
\end{tabular}

${ }^{*}$ Log-rank test; ${ }^{* *}$ Cox regression model with multiple variables(disease-free survival, number of metastatic sites, liver metastases, lung metastases, skeletal metastases, lymph node metastases, chemotherapy response, baseline LDH level and LDH level Changes).

advanced TNBC patients. More research is needed to confirm these findings and to understand the mechanism underlying LDH and tumor progression.

\section{MATERIALS AND METHODS}

A retrospective review was undertaken with female patients with advanced TNBC $(n=131)$ who received first-line chemotherapy at Fudan University Shanghai Cancer Center between 2005 and 2013. Patients were included if they had pathological confirmation of TNBC, biopsy or radiological confirmation of tumor recurrence or distant metastasis, good ECOG performance status, and available data on baseline and post-treatment serum LDH levels (see patient characteristics in Table 1). Patients were excluded if they had complications from other types of malignancies, no evidence of tumor recurrence or distant metastasis, acute heart failure, or severe renal or liver dysfunction.

Patients' medical charts were reviewed to obtain data about clinical features, treatment information, and serum LDH levels. Menopause status was defined according to the National Comprehensive Cancer Network 
Table 5: The difference in clinical response (CR or PR vs SD or PD) according to various clinical characteristics

\begin{tabular}{|c|c|c|c|c|c|}
\hline \multirow[b]{2}{*}{ Variables } & \multicolumn{3}{|c|}{ Clinical response } & \multicolumn{2}{|c|}{ Logistic regression model } \\
\hline & CR or PR n (\%) & $\begin{array}{c}\text { SD or PD } \\
\text { n (\%) }\end{array}$ & $P^{*}$ & OR $(95 \% C I)$ & $\boldsymbol{P}^{* *}$ \\
\hline Age & & & 0.745 & & \\
\hline$\leq 40$ years & $19(61.3 \%)$ & $12(38.7 \%)$ & & & \\
\hline$>40$ years & $58(58.0 \%)$ & $42(42.0 \%)$ & & & \\
\hline Menopausal status & & & 0.976 & & \\
\hline Pre-menopause & $44(58.7 \%)$ & $31(41.3 \%)$ & & & \\
\hline Post-menopause & $33(58.9 \%)$ & $23(41.1 \%)$ & & & \\
\hline Number of metastatic sites & & & 0.413 & & \\
\hline 1 & $26(65.0 \%)$ & $14(35.0 \%)$ & & & \\
\hline 2 & $20(62.5 \%)$ & $12(37.5 \%)$ & & & \\
\hline$\geq 3$ & $31(52.5 \%)$ & $28(47.5 \%)$ & & & \\
\hline Liver metastases & & & 0.008 & & \\
\hline Absent & $62(66.0 \%)$ & $32(34.0 \%)$ & & Ref. & \\
\hline Present & $15(40.5 \%)$ & $22(59.5 \%)$ & & $4.267(1.703-10.692)$ & 0.002 \\
\hline Lung metastases & & & 0.077 & & \\
\hline Absent & $35(51.5 \%)$ & $33(48.5 \%)$ & & & \\
\hline Present & $42(66.7 \%)$ & $21(33.3 \%)$ & & & \\
\hline Skeletal metastases & & & 0.415 & & \\
\hline Absent & $51(61.4 \%)$ & $32(38.6 \%)$ & & & \\
\hline Present & $26(54.2 \%)$ & $27(45.8 \%)$ & & & \\
\hline Lymph node metastases & & & 0.420 & & \\
\hline Absent & $25(64.1 \%)$ & $14(35.9 \%)$ & & & \\
\hline Present & $52(56.5 \%)$ & $40(43.5 \%)$ & & & \\
\hline Disease-free survival & & & 0.365 & & \\
\hline$>12$ months & $26(51.0 \%)$ & $25(49.0 \%)$ & & & \\
\hline$\leq 12$ months & $44(62.9 \%)$ & $26(37.1 \%)$ & & & \\
\hline Primary metastatic & $7(70.0 \%)$ & $3(30.0 \%)$ & & & \\
\hline Baseline serum LDH & & & 0.415 & & \\
\hline Normal & $43(55.8 \%)$ & $34(44.2 \%)$ & & & \\
\hline Abnormal & $34(63.0 \%)$ & $20(37.0 \%)$ & & & \\
\hline LDH level Changes & & & 0.005 & & \\
\hline Group 1 & $10(40.0 \%)$ & $15(60.0 \%)$ & & Ref. & \\
\hline Group 2 & $8(50.0 \%)$ & $8(50.0 \%)$ & & $0.555(0.145-2.121)$ & 0.390 \\
\hline Group 3 & $24(85.7 \%)$ & $4(14.3 \%)$ & & $0.074(0.018-0.311)$ & $<0.001$ \\
\hline Group 4 & $35(56.5 \%)$ & $27(43.5 \%)$ & & $0.537(0.201-1.437)$ & 0.216 \\
\hline
\end{tabular}

"chi-squared test; "Logistic regression model with multiple variables (age, menopausal status, number of metastatic sites, liver metastases, lung metastases, skeletal metastases, lymph node metastases, disease-free survival, baseline serum LDH and LDH level Changes).

(NCCN) Guidelines (NCCN Clinical practice guidelines in oncology. Breast Cancer V1 2017 [36]). Serum LDH levels were measured using the Roche Cobas 8000 system (Roche, Indianapolis, IN, USA). All patients were told to fast after midnight on the day of the blood test. Baseline serum LDH levels were measured within 2 weeks before administering first-line chemotherapy. If multiple measurements were taken, the average of the measurements was used. Patients were stratified to normal baseline $\mathrm{LDH}(\leq 250 \mathrm{IU} / \mathrm{L})$ and abnormal baseline
LDH (>250 IU/L) groups. Post-treatment serum LDH measurements were conducted after two cycles of firstline chemotherapy. According to changes between baseline and post-treatment $\mathrm{LDH}$ values, patients were divided into four groups: Group 1 included patients with abnormal post-treatment serum LDH levels higher than baseline; Group 2 included patients with post-treatment serum LDH levels that decreased but did not return to normal; Group 3 included patients with post-treatment serum LDH levels that decreased to normal; and Group 4 included patients 
with normal baseline and post-treatment LDH levels. Tumor responses to chemotherapy (chemotherapeutic response) were assessed and graded as complete response (CR), partial response (PR), stable disease (SD), or progressive disease (PD) according to the revised RECIST guideline (version 1.1) [37]. Clinical response was defined as either CR or PR. Survival information was collected from medical records or telephone interviews. The diseasefree interval (DFI) was defined as the period between surgical resection and diagnosis of tumor recurrence or distant metastasis. Progression-free survival (PFS) was defined as the period between the start of chemotherapy and the first time of documented PD. Overall survival (OS) was defined as the period between diagnosis of local recurrence or distant metastasis and death or last followup. Objective response rate (ORR) was defined as the percent of patients with CR and PR.

We used SPSS 21.0 statistical software to analyze data, and a two-tailed $p$ value $<0.05$ was considered statistically significant. A multiple comparisons analysis was not mandatory because the goal of this exploratory analysis was to identify hypotheses that could be subject to more rigorous future examinations. A chi-squared test was used to investigate the association between baseline serum LDH levels and clinical features, as well as the association between various risk factors and chemotherapy response. Logistic regression was used to analyze the association between serum LDH levels and potentially relevant factors, as well as the association between the chemotherapeutic response and potential relevant factors. PFS and OS were determined according to the KaplanMeier method, and intergroup comparison according to the variables in Table 1 was performed by the log-rank test. Subsequently, the relevant variables identified by univariate analysis with a significant association with PFS and OS $(P<0.1)$ and two clinically potentially important variables (age and type of first-line treatment) were analyzed using the Cox regression model to determine the independent prognostic factors for PFS and OS.

\section{CONFLICTS OF INTEREST}

The authors have no conflicts of interest to declare.

\section{FUNDING}

This research was supported by a grant from Shanghai Municipal Commission of Health and Family Planning (No. 201640069) and the Shanghai Natural Science Foundation (No. 17ZR1405700).

\section{REFERENCES}

1. Boyle P. The globalisation of cancer. Lancet. 2006; 368:629-30.
2. Jemal A, Bray F, Center MM, Ferlay J, Ward E, Forman D. Global cancer statistics. CA Cancer J Clin. 2011; 61:69-90.

3. Carey L, Winer E, Viale G, Cameron D, Gianni L. Triple-negative breast cancer: disease entity or title of convenience? Nat Rev Clin Oncol. 2010; 7:683-692.

4. Yamamoto N, Watanabe T, Katsumata N, Omuro Y, Ando M, Fukuda H, Takue Y, Narabayashi M, Adachi I, Takashima S. Construction and validation of a practical prognostic index for patients with metastatic breast cancer. J Clin Oncol. 1998; 16:2401-2408.

5. Kemp M, Donovan J, Higham H, Hooper J. Biochemical markers of myocardial injury. Br J Anaesth. 2004; 93:6373.

6. Drent M, Cobben NA, Henderson RF, Wouters EF, van Dieijen-Visser M. Usefulness of lactate dehydrogenase and its isoenzymes as indicators of lung damage or inflammation. Eur Respir J. 1996; 9:1736-1742.

7. Kato GJ, McGowan V, Machado RF, Little JA, Taylor J 6th, Morris CR, Nichols JS, Wang X, Poljakovic M, Morris SM $\mathrm{Jr}$, Gladwin MT. Lactate dehydrogenase as a biomarker of hemolysis-associated nitric oxide resistance, priapism, leg ulceration, pulmonary hypertension, and death in patients with sickle cell disease. Blood. 2006; 107:2279-2285.

8. Wulaningsih W, Holmberg L, Garmo H, Malmstrom H, Lambe M, Hammar N, Walldius G, Jungner I, Ng T, Van Hemelrijck M. Serum lactate dehydrogenase and survival following cancer diagnosis. Br J Cancer. 2015; 113:13891396.

9. Liu X, Meng QH, Ye Y, Hildebrandt MA, Gu J, Wu X. Prognostic significance of pretreatment serum levels of albumin, LDH and total bilirubin in patients with nonmetastatic breast cancer. Carcinogenesis. 2015; 36:243-248.

10. Brown JE, Cook RJ, Lipton A, Coleman RE. Serum lactate dehydrogenase is prognostic for survival in patients with bone metastases from breast cancer: a retrospective analysis in bisphosphonate-treated patients. Clin Cancer Res. 2012; 18:6348-55.

11. Dent R, Trudeau M, Pritchard KI, Hanna WM, Kahn HK, Sawka CA, Lickley LA, Rawlinson E, Sun P, Narod SA. Triple-negative breast cancer: clinical features and patterns of recurrence. Clin Cancer Res. 2007; 13:4429-4434.

12. Kassam F, Enright K, Dent R, Dranitsaris G, Myers J, Flynn C, Fralick M, Kumar R, Clemons M. Survival outcomes for patients with metastatic triple-negative breast cancer: implications for clinical practice and trial design. Clin Breast Cancer. 2009; 9:29-33.

13. Hu XC, Zhang J, Xu BH, Cai L, Ragaz J, Wang ZH, Wang BY, Teng YE, Tong ZS, Pan YY, Yin YM, Wu CP, Jiang $\mathrm{ZF}$, et al. Cisplatin plus gemcitabine versus paclitaxel plus gemcitabine as first-line therapy for metastatic triple-negative breast cancer (CBCSG006): a randomised, open-label, multicentre, phase 3 trial. Lancet Oncol. 2015; 16:436-46.

14. Tutt A, Ellis P, Kilburn L, Gilett C, Pinder S, Abraham J, Barrett S, Barrett-Lee P, Chan S, Cheang M, Fox L, Grigoriadis 
A, Harper-Wynne C, et al. The TNT trial: a randomized phase III trial of carboplatin (C) compared with docetaxel (D) for patients with metastatic or recurrent locally advanced triple negative or BRCA1/2 breast cancer (CRUK/07/012). Cancer Res. 2015; 75:S3-01.

15. O’Shaughnessy J, Schwartzberg L, Danso MA, Miller KD, Rugo HS, Neubauer M, Robert N, Hellerstedt B, Saleh M, Richards P, Specht JM, Yardley DA, Carlson RW, et al. Phase III Study of Iniparib Plus Gemcitabine and Carboplatin Versus Gemcitabine and Carboplatin in Patients With Metastatic TripleNegative Breast Cancer. J Clin Oncol. 2014; 32:3840-3847.

16. Nagle SJ, Woo K, Schuster SJ, Nasta SD, Stadtmauer E, Mick R, Svoboda J. Outcomes of patients with relapsed/ refractory diffuse large B-cell lymphoma with progression of lymphoma after autologous stem cell transplantation in the rituximab era. Am J Hematol. 2013; 88:890-4.

17. Garbe C, Peris K, Hauschild A, Saiag P, Middleton M, Spatz A, Grob JJ, Malvehy J, Newton-Bishop J, Stratigos A, Pehamberger H, Eggermont AM. Diagnosis and treatment of melanoma. European consensus-based interdisciplinary guideline--Update 2012. Eur J Cancer. 2012; 48:2375-2390.

18. Lee DS, Park KR, Kim SJ, Chung MJ, Lee YH, Chang JH, Kang JH, Hong SH, Kim MS, Kim YS. Serum lactate dehydrogenase levels at presentation in stage IV non-small cell lung cancer: predictive value of metastases and relation to survival outcomes. Tumour Biol. 2016; 37:619-25.

19. Zhang P, Xi M, Li QQ, He LR, Liu SL, Zhao L, Shen JX, Liu MZ. The modified glasgow prognostic score is an independent prognostic factor in patients with inoperable thoracic esophageal squamous cell carcinoma undergoing chemoradiotherapy. J Cancer. 2014; 5:689-695.

20. Zhao Z, Han F, Yang S, Hua L, Wu J, Zhan W. The Clinicopathologic Importance of Serum Lactic Dehydrogenase in Patients with Gastric Cancer. Dis Markers. 2014; 2014.

21. Tas F, Karabulut S, Ciftci R, Sen F, Sakar B, Disci R, Duranyildiz D. Serum levels of LDH, CEA, and CA199 have prognostic roles on survival in patients with metastatic pancreatic cancer receiving gemcitabine-based chemotherapy. Cancer Chemother Pharmacol. 2014; 73:1163-1171.

22. Cetin B, Afsar B, Deger SM, Gonul II, Gumusay O, Ozet A, Benekli M, Coskun U, Buyukberber S. Association between hemoglobin, calcium, and lactate dehydrogenase variability and mortality among metastatic renal cell carcinoma. Int Urol Nephrol. 2014; 46:1081-1087.

23. Petrelli F, Cabiddu M, Coinu A, Borgonovo K, Ghilardi M, Lonati V, Barni S. Prognostic role of lactate dehydrogenase in solid tumors: a systematic review and meta-analysis of 76 studies. Acta Oncol. 2015; 54:961-970.

24. Faloppi L, Scartozzi M, Bianconi M, Svegliati Baroni G, Toniutto P, Giampieri R, Del Prete M, De Minicis S, Bitetto D, Loretelli C, D’Anzeo M, Benedetti A, Cascinu S. The role of $\mathrm{LDH}$ serum levels in predicting global outcome in HCC patients treated with sorafenib: implications for clinical management. BMC Cancer. 2014; 14:110.
25. Scartozzi M, Giampieri R, Maccaroni E, Del Prete M, Faloppi L, Bianconi M, Galizia E, Loretelli C, Belvederesi L, Bittoni A, Cascinu S. Pre-treatment lactate dehydrogenase levels as predictor of efficacy of first-line bevacizumab-based therapy in metastatic colorectal cancer patients. Br J Cancer. 2012; 106:799-804.

26. Koukourakis MI, Giatromanolaki A, Sivridis E, Gatter KC, Trarbach T, Folprecht G, Shi MM, Lebwohl D, Jalava T, Laurent D, Meinhardt G, Harris AL. Prognostic and predictive role of lactate dehydrogenase 5 expression in colorectal cancer patients treated with PTK787/ZK 222584 (vatalanib) antiangiogenic therapy. Clin Cancer Res. 2011; 17:4892-4900.

27. Majumder PK, Febbo PG, Bikoff R, Berger R, Xue Q, McMahon LM, Manola J, Brugarolas J, McDonnell TJ, Golub TR, Loda M, Lane HA, Sellers WR. mTOR inhibition reverses Akt-dependent prostate intraepithelial neoplasia through regulation of apoptotic and HIF-1dependent pathways. Nat Med. 2004; 10:594-601.

28. Zha X, Wang F, Wang Y, He S, Jing Y, Wu X, Zhang H. Lactate dehydrogenase $\mathrm{B}$ is critical for hyperactive mTORmediated tumorigenesis. Cancer Res. 2011; 71:13-18.

29. Youssef RF, Cost NG, Darwish OM, Margulis V. Prognostic markers in renal cell carcinoma: A focus on the 'mammalian target of rapamycin' pathway. Arab J Urol. 2012; 10:110-117.

30. McFate T, Mohyeldin A, Lu H, Thakar J, Henriques J, Halim ND, Wu H, Schell MJ, Tsang TM, Teahan O, Zhou $\mathrm{S}$, Califano JA, Jeoung NH, et al. Pyruvate dehydrogenase complex activity controls metabolic and malignant phenotype in cancer cells. J Biol Chem. 2008; 283:22700-22708.

31. Pouysségur J, Dayan F, Mazure NM. Hypoxia signalling in cancer and approaches to enforce tumour regression. Nature. 2006; 441:437-443.

32. Parks SK, Chiche J, Pouysségur J. Disrupting proton dynamics and energy metabolism for cancer therapy. Nat Rev Cancer. 2013; 13:611-623.

33. Lee DS, Park KR, Kim SJ, Chung MJ, Lee YH, Chang JH, Kang JH, Hong SH, Kim MS, Kim YS. Serum lactate dehydrogenase levels at presentation in stage IV non-small cell lung cancer: predictive value of metastases and relation to survival outcomes. Tumour Biol. 2016; 37:619-625.

34. Radecka B, Litwiniuk M. Breast cancer in young women. Ginekol Pol. 2016; 87:659-63.

35. Brindley CO, Francis FL. Serum lactic dehydrogenase and glutamic-oxaloacetic transminase correlations with measurements of tumor masses during therapy. Cancer Res. 1963; 23:112-117.

36. NCCN Clinical practice guidelines in oncology. Breast Cancer, Version 1. 2017.

37. Eisenhauer EA, Therasse P, Bogaerts J, Schwartz LH, Sargent D, Ford R, Dancey J, Arbuck S, Gwyther S, Mooney M, Rubinstein L, Shankar L, Dodd L, et al. New response evaluation criteria in solid tumours: revised RECIST guideline (version 1.1). Eur J Cancer. 2009; 45:228-247. 